\title{
Suicídio na Adolescência: Representações dos pacientes e suas Famílias
}

\author{
Nice Dias Gonçalve ${ }^{1}$; Norma Faustino Rocha Randemark ${ }^{2}$
}

\begin{abstract}
Resumo: A adolescência é uma fase na vida do ser humano marcada por intensas mudanças, que embora naturais e esperadas, podem levar a inúmeras situações, dentre elas a depressão e dependendo do seu nível, ao intento suicida. A pesquisa objetiva apreender as representações dos adolescentes acerca da morte e do morrer; identificar quais os determinantes socioculturais do intento suicida em adolescentes; compreender a dinâmica afetivo/relacional do adolescente com a rede sócio familiar e sua implicação na produção do desejo suicida e apreender as representações de usuários e familiares acerca da assistência, no âmbito hospitalar, aos adolescentes com história de tentativa de suicídio. O estudo consiste numa pesquisa de campo do tipo exploratório descritiva com abordagem qualitativa, tendo como lócus um hospital geral da rede municipal de saúde, na cidade de Juazeiro do Norte/CE. Os sujeitos foram adolescentes admitidos na emergência do hospital por tentativa de suicídio e seu familiar/responsável. Os instrumentos utilizados foram formulário de caracterização com roteiro de história de vida dos adolescentes e entrevistas semiestruturadas com questões norteadoras. Como resultados, a morte foi representada pelos adolescentes conforme suas crenças e vivências, o seu significado foi evidenciado como meio de resolução dos problemas, e o suicídio trazido como ato impulsivo. Para a família, a experiência foi negativa. Esta pesquisa possibilitou a compreensão dos determinantes na produção do desejo suicida em adolescentes, e dessa forma, pode contribuir para identificar e minimizar o potencial de risco de recidiva para o suicídio e promover sua reabilitação psicossocial.
\end{abstract}

Palavras-chave: Suicídio. Adolescência. Família. Assistência.

\section{Teenage Suicide: Representations Of Patients And Their Families}

\begin{abstract}
Adolescence is a stage in human life marked by intense changes, that although natural and expected, can lead to numerous situations, among them depression and depending on your level, with suicidal intent. The research aims to grasp the representations of adolescents about death and dying; identify the sociocultural determinants of suicidal attempt in adolescents; understand the emotional/relational dynamics of adolescent family member with the network and its implication in the production of suicidal desire and seize the representations of users and families about care in hospital settings, adolescents with a history of suicide attempt. The study consists of a field survey of the descriptive exploratory qualitative approach, with the locus of a general hospital municipal health in the city of Juazeiro/EC. Subjects were adolescents admitted to the hospital emergency room for attempted suicide and their family/guardian. The instruments used were form featuring a screenplay by life story of teenagers and semi-structured interviews with guiding questions. As a result, death was represented by teenagers as their beliefs and experiences, their meaning was evidenced as a means of solving problems, and suicide brought as impulsive act. For the family, the experience was negative. This research led to the understanding of the determinants for the production of suicidal desire in adolescents, and thus can help to identify and minimize the potential risk of recurrence for suicide and promote their psychosocial rehabilitation.
\end{abstract}

Keywords: Suicide. Adolescence. Family. Assistance.

\footnotetext{
${ }^{1}$ Enfermeira pela Universidade Regional do Cariri (URCA), Especialista em Urgência e Emergência pela Faculdade Integrada de Patos (FIP) e Mestre em Saúde da Criança e do Adolescente pela Universidade Estadual do Ceará (UECE) enf-nice@hotmail.com

${ }^{2}$ Enfermeira e Psicóloga. Doutora em enfermagem (EEUSP/2009). Docente do colegiado de Enfermagem da Universidade Estadual do Ceará.
} 


\section{Introdução}

No transcorrer da vida, o homem passa por inúmeras fases que vão da infância à velhice, dentre elas, a adolescência, período onde se observa a presença de mudanças que afetam todo o organismo e que são responsáveis pelo amadurecimento e formação de cada indivíduo.

Mais que uma etapa da nossa existência, a adolescência é uma fase especial no decorrer da formação do homem, determinando transformações, as quais conduzem à maturidade fisiológica, psicológica e social inerente ao ser humano (FROTA, 2007).

A Organização Mundial da Saúde (OMS) define a adolescência como a segunda década da vida, constituindo a faixa etária de 10 a 19 anos que, em geral, se inicia com as mudanças corporais da puberdade e termina com a inserção social, profissional e econômica. A pré-adolescência é a fase entre 10 a 14 anos e a adolescência, propriamente dita, entre 15 a 19 anos, sendo a juventude incluída ainda dos 15 aos 24 anos (BRASIL, 2007).

Compreendemos que nesse ciclo de vida, independente da classe social, da raça a qual o indivíduo pertença ou qualquer outro fator externo, o nosso corpo sofre as consequências das alterações hormonais promotoras do crescimento e desenvolvimento, fato que implica em medo, dúvidas e descobertas. Por outro lado, a forma como cada jovem enfrenta tal fase é intensamente influenciada pelo contexto sociocultural onde ele está inserido, de maneira que os anseios vivenciados num adolescer permeados por conflitos familiares, preconceitos, drogas e violência podem desencadear graves crises existenciais.

Com efeito, sabemos hoje que toda essa conjuntura pode gerar uma suscetibilidade aos vários pontos que atingem a saúde mental do indivíduo, sendo assim, os adolescentes se mostram tão vulneráveis à depressão quanto os adultos, devendo ser encarada como um distúrbio que pode atingir seriamente todas as faixas etárias.

Dessa forma, entendemos que a adolescência é uma época na vida do ser humano de intensas mudanças que, embora, naturais do ponto de vista evolutivo fazem com que os jovens experimentem níveis crescentes de ansiedade e angústia, de maneira que, se outros agentes estressantes forem acrescidos podem conduzir ao comportamento suicida.

Essas situações de risco comprometem a saúde física e mental dos adolescentes levando-os, mais frequentemente, ao atendimento aos serviços de urgência devido às manifestações emocionais $\mathrm{e}$ comportamento suicida (NUNES, ANDRADE; 2009).

Ao nos alertar para essa problemática, Souza (2010) assinala que, dentre as principais causas de mortalidade na adolescência, o suicídio apresenta-se como o terceiro maior responsável, em todo o mundo. Esses elevados índices de tentativas e ideação suicida caracterizam essa temática como um importante problema de saúde pública. 
Diante do exposto, consideramos importante olharmos atentamente para essa fase e apreendermos precocemente, por mais que sejam complexas as condições que levam esses jovens a atentar contra sua própria vida, mediante apreensão das suas vivências e de seus familiares, do processo de recuperação no hospital sob os cuidados da equipe de enfermagem.

No que diz respeito ao meu interesse por essa temática, esta surgiu no curso da minha experiência profissional como enfermeira, trabalhando na emergência de um hospital público da rede municipal de saúde destinada aos atendimentos de urgência e emergência na cidade de Juazeiro do Norte/CE.

Nesse contexto, pude presenciar inúmeros casos de adolescentes vítimas da tentativa de suicídio e, nessas ocasiões, sentia-me tomada pelo sentimento de impotência face aos enigmas que permeiam essa clientela, sobre o que os leva a cometer atos que afetam a sua integridade física e mental. Observei, ainda, no cotidiano de uma emergência hospitalar que as tentativas de autoextermínio ocorrem de variadas formas, desde a ingestão de substancias tóxicas, como venenos e excesso de medicamentos, até o próprio ato de enforcar-se, e entre as mais diversas idades e ambos os sexos.

A minha inquietação frente à realidade acima referida motivou o interesse em desenvolver este estudo, o qual se justifica porque, embora, saibamos serem inúmeros os determinantes envolvidos nesse desfecho, o aprofundamento dessa questão mediante reflexão acerca dos determinantes intrínsecos e extrínsecos que atuam de forma sinérgica na identidade e personalidade do sujeito e na produção do desejo suicida, além da apreensão das condições concretas que favorecem as ocorrências desse intento em adolescentes na sociedade moderna capitalista podem, também, ampliar a compreensão dos profissionais de saúde e fornecer-lhes subsídios para que possam atuar de forma mais eficaz na prevenção dos intentos suicidas, no combate às suas recidivas, na promoção da saúde e no aumento da expectativa de vida de jovens expostos às condições de risco.

Sendo assim, esse estudo objetiva apreender as representações dos adolescentes acerca da morte e do morrer, identificar quais os determinantes socioculturais do intento suicida em adolescentes, compreender a dinâmica afetivo/relacional do adolescente com a rede sócio-familiar e sua implicação na produção do desejo suicida, bem como apreender as representações de usuários e familiares acerca da assistência, no âmbito hospitalar, aos adolescentes com história de tentativa de suicídio. 


\section{Trajetória Metodológica}

\section{Tipo de pesquisa}

Este estudo constituiu numa pesquisa de campo do tipo exploratório descritiva com abordagem qualitativa.

\section{Cenário da pesquisa}

O lócus da nossa pesquisa foi um Hospital Geral da rede municipal de saúde na cidade de Juazeiro do Norte/CE.

A cidade de Juazeiro do Norte, por sua vez, está localizada no extremo sul do Estado do Ceará, no eixo da região do Cariri, distante cerca de $560 \mathrm{~km}$ de Fortaleza, a capital do Estado (WALKER, 2002).

A escolha por esse cenário é justificada pelo grande número de atendimentos, sendo uma média de 600 pacientes/dia, totalizando cerca de 18.000 atendimentos/mês. Para o acolhimento, a unidade conta com uma equipe multiprofissional que atua nas 24 horas, tendo como público-alvo pessoas de ambos os sexos, com idade superior ou igual a 13 anos e que necessitem de algum tipo de atendimento de caráter emergencial.

A dinâmica da assistência se dá de acordo com o quadro clínico do paciente, podendo o mesmo ser encaminhado para outros de referência, quando a unidade em questão não possuir condições necessárias para o fornecimento do suporte adequado. Contudo, essa decisão pode variar conforme o plantonista da unidade, posto que ainda não foram implantados protocolos que subsidiem as decisões a serem tomadas. A referida unidade de saúde atua com essa dinâmica desde 2008, fornecendo atendimento emergencial aos habitantes que residem na cidade.

\section{Sujeitos da pesquisa}

Foram sujeitos desta pesquisa dois adolescentes admitidos na emergência do hospital por tentativa de suicídio e seus respectivos familiares e/ou responsáveis legais.

A escolha dos adolescentes obedeceu aos seguintes critérios de inclusão: jovens de ambos os sexos, na faixa etária de 14 a 19 anos que deram entrada na emergência do hospital lócus da nossa pesquisa por tentativa de suicídio, entre os anos de 2012 e 2013 e que, na ocasião, moravam com sua família de origem e que, no momento da entrevista, apresentassem condições físicas e psicoemocionais preservadas, capacidade de verbalização e de compreensão do processo o qual iria fazer parte, de forma que estivessem aptos a aceitar por livre e espontânea vontade participar da pesquisa. Foram considerados como critério de exclusão aqueles que apresentassem dificuldade 
cognitiva e/ou emocional capaz de interferir nessa escolha, tais como depressão profunda, agitação psicomotora, confusão mental e déficit de memória e/ou inteligência.

Quanto à inclusão dos familiares dos adolescentes nas entrevistas considerou-se como critério de inclusão ser genitor (a) do adolescente e/ou seu responsável legal, morar com ele na mesma residência e ter acompanhado o paciente durante a sua internação da emergência e que tenha se afirmado capaz de falar dessa experiência.

Quanto à abordagem dos adolescentes eleitos, gostaríamos de esclarecer que em face da não incidência de casos novos na emergência no período previsto para a coleta de dados, foi necessária a realização de uma busca nos prontuários a fim de identificar os adolescentes que deram entrada na emergência entre os anos de 2012 e 2013, e que atendessem aos critérios de inclusão e, posteriormente, entrar em contato com eles. Para tanto, de posse das fichas de admissão, realizou-se identificação dos endereços com a ajuda de um GPS (Sistema de Posicionamento Global) e contato prévio por telefone com os sujeitos a fim de solicitar sua permissão para abordá-los em sua residência. Nesse processo foram selecionados três prontuários, porém, somente dois foram contatados, uma vez que o terceiro sujeito não residia no local indicado e nem possuía o mesmo contato telefônico fornecido pelos registros do hospital.

Após receber permissão, realizou-se a primeira visita, momento em que houve apresentações e se prestou esclarecimento acerca do estudo, formalizando o convite para que os mesmos participassem como sujeitos da pesquisa. E, após se obter expressão positiva de aceitação e confiança, marcou-se um segundo momento para realizar o procedimento de coleta dos achados.

As entrevistas ocorreram nas residências dos sujeitos e em local de acesso restrito, de forma a garantir a privacidade do entrevistado. Após se esclarecer todas as dúvidas sobre os procedimentos da pesquisa e direitos do pesquisado e obter aceitação verbal do adolescente e consentimento formal do familiar responsável mediante assinatura do termo de consentimento livre esclarecido iniciou-se a coleta dos achados com a aplicação do formulário de caracterização dos sujeitos, roteiro de história de vida e entrevista. Após o término da entrevista com o adolescente, ainda, no mesmo dia, realizou-se a entrevista do familiar do adolescente.

\section{Instrumentos e procedimentos}

O ingresso no campo foi precedido dos seguintes procedimentos administrativos, para tanto, após ser aprovado pela banca de qualificação, o projeto foi encaminhado à direção do hospital, mediante oficio solicitando autorização para realização da pesquisa, acrescido a carta de anuência da Secretaria Municipal de Saúde e a carta de aprovação do Comitê de Ética em Pesquisa ratificado por meio do parecer $\mathrm{N}^{\circ} 364.477$ de 2013. 
Para a coleta dos achados foram utilizados: formulário de caracterização dos adolescentes com roteiro de historia de vida e entrevista semiestruturadas com questões norteadoras, esta aplicada a todos os sujeitos da pesquisa.

Levando em consideração que o ato suicida envolve múltiplos agravantes que emergem no curso de enfrentamento dos problemas insertos na sua trajetória pessoal optou-se pela história de vida focal. O interesse em explorar aspectos complexos como valor da vida, significância familiar, traumas, crenças e constituição de redes sociais, elementos culturais, entre outros, foi o que justificou a adoção dessa estratégia metodológica.

Diante de suas histórias de vida, para melhor apresentá-las e entende-las, optamos pela construção do genograma familiar de cada adolescente, sendo, este capaz de resumir e descrever facilmente todas as ligações entre o sujeito foco e os membros de suas famílias, bem como suas principais enfermidades e dificuldades explicitadas em seu convívio.

No tocante à abordagem dos familiares, mediante entrevistas semiestruturadas, as questões norteadoras visaram apreender as experiências dos sujeitos no cuidado dos adolescentes tanto no contexto hospitalar, por ocasião de sua entrada na emergência, como no domicilio.

Após cada entrevista, foram registradas pelo pesquisador, num diário de campo, as impressões, eventos inusitados, dificuldades, angústias e dúvidas surgidas no curso da pesquisa e que constituíram achados subjetivos do pesquisador incorporados à análise.

As entrevistas foram gravadas em MP3 e as falas foram transcritas na integra para posterior análise.

Aos sujeitos foi assegurado que todo o conteúdo das gravações ficará em nossa posse por cinco anos, guardada de forma segura de modo que ninguém, exceto os pesquisadores, tenha acesso a essas informações e que seu conteúdo não terá outros fins senão a publicação de trabalhos de pesquisa científica a ser elaborado pelos pesquisadores responsáveis. Após cinco anos, todo material será descartado mediante incineração.

\section{Aspectos éticos e legais da pesquisa}

Por se tratar de uma pesquisa que envolve seres humanos, o estudo foi fundamentado de acordo com a Resolução N N $^{\circ}$ 466/2012, do Conselho Nacional de Saúde (CNS/MS). Torna-se importante assinalar que levamos em conta as questões éticas contidas nessa resolução no que diz respeito ao envolvimento com seres humanos, tais como a autonomia, não maleficência, beneficência e justiça, além de que nos comprometemos em assegurar os direitos e deveres da comunidade científica frente aos sujeitos da pesquisa e ao Estado (BRASIL, 1996). 


\section{Método de análise dos achados}

Neste estudo, os achados da pesquisa foram submetidos ao método de Analise do Discurso conforme proposto por Fiorin. O referido autor considera a análise do discurso fenômeno multiforme e heteróclito, intimamente relacionado com a linguagem, vê a fala por diversos ângulos, tornando explícitos mecanismos implícitos na interpretação dos textos (FIORIN, 2005).

A Análise do Discurso centraliza o referencial teórico para as reflexões sobre a linguagem, coloca-se em relação às Ciências Humanas refletindo as questões de sentido inseridas numa relação entre sujeito, linguagem e história e tem como objeto o (inter) discurso (KRONKA, 2003).

O tratamento dos achados compreendeu a leitura atenta e repetida de todo o texto a fim de corrigir distorções e focalizar figuras e temas. Os temas e seus subtemas foram agrupados em categorias empíricas. A análise, pautada na literatura pertinente, se deu mediante contextualização histórica e social, olhar crítico e reconstrução textual das crenças, concepções e valores insertos no discurso, ressaltando seus aspectos contraditórios.

\section{Análise e Discussão dos Achados}

\section{Perfil dos adolescentes}

Embasados no roteiro de história de vida de cada adolescente, optamos por contemplar uma análise rápida de suas principais características, construindo um genograma familiar de cada sujeito da pesquisa.

A seguir apresentamos os genogramas familiares, que abordam respectivamente os adolescentes 1 e 2 , dessa forma coligamos os elos entre os jovens e suas famílias. A legenda logo abaixo favorece a identificação dos personagens, revelando o significado de cada figura.

Em seguida fizemos uma breve descrição de cada genograma. 
Genograma Familiar- Adolescente 1

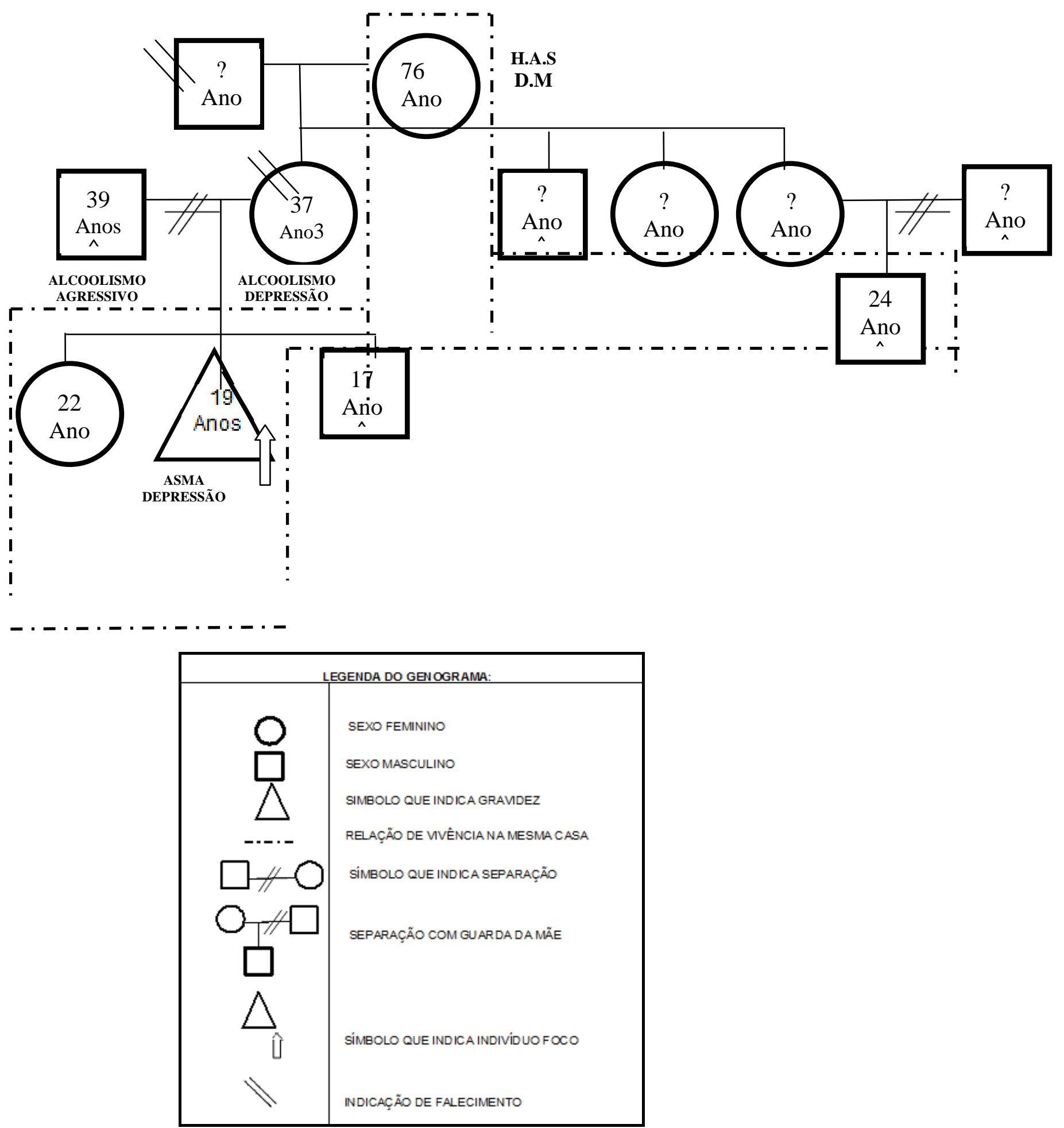

FIGURA 1 - Perfil do Adolescente 1 
O genograma acima apresenta como membro principal a adolescente de 19 anos, grávida, tendo como doença base, depressão e asma; sendo a segunda filha num total de três. Seus pais carregavam morbidades como alcoolismo e depressão, e após diversos conflitos se separaram, gerando posteriormente outras conturbações que acarretaram vários internamentos hospitalares em sua mãe, e assim seu óbito. Sendo a adolescente e sua irmã acolhidas, permanentemente, pela avó materna, 76 anos, viúva e portadora de doenças crônicas como Diabetes Mellitus e Hipertensão Arterial, que por sua vez já abrigava outro neto.

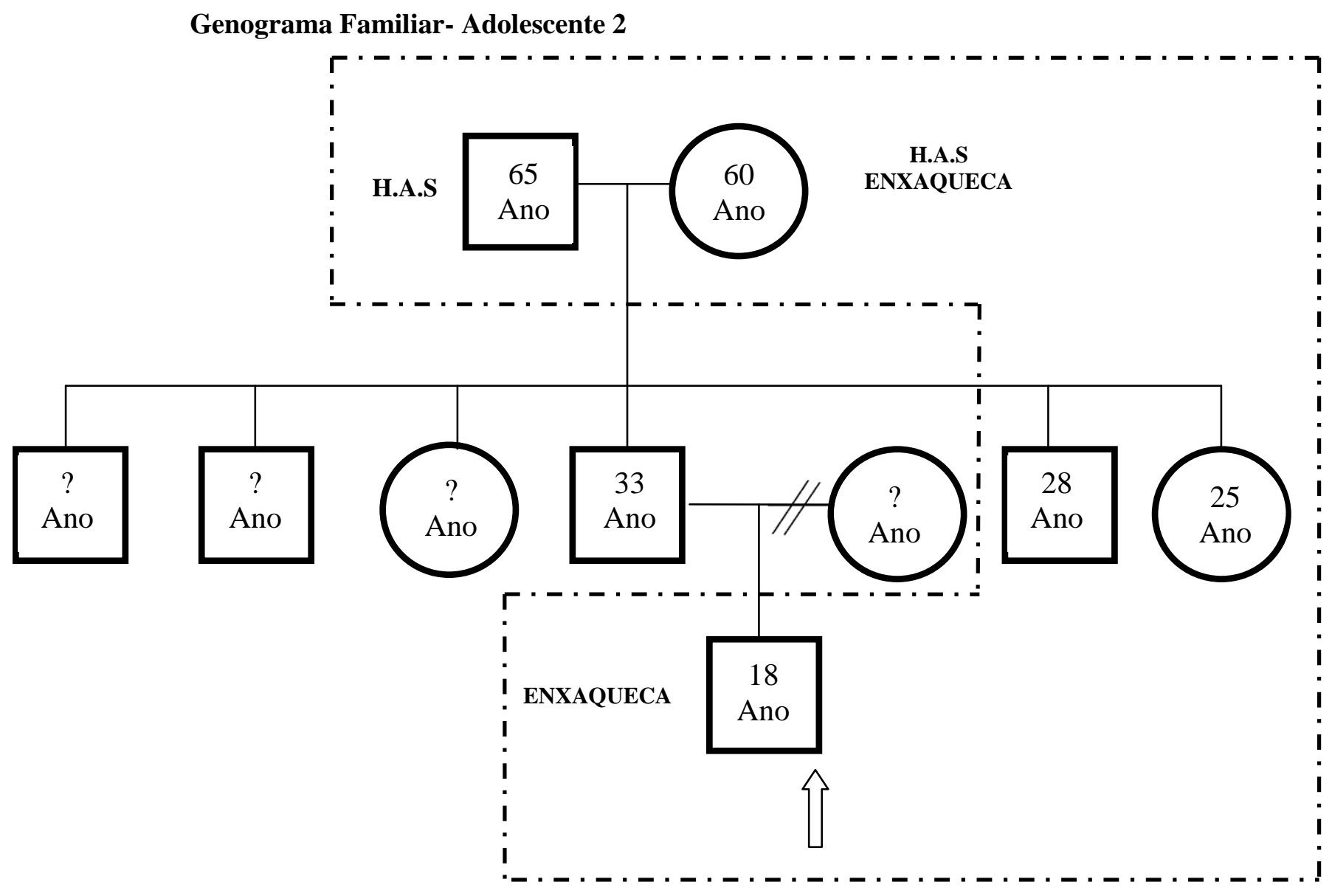




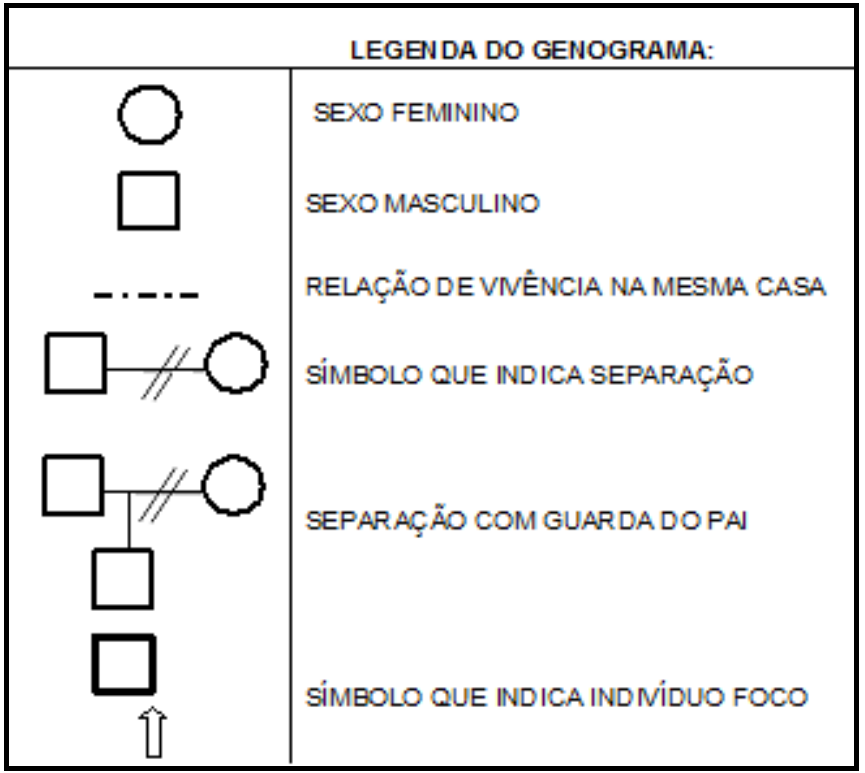

FIGURA 2 - Perfil do Adolescente 2

O genograma familiar do adolescente 2 traz um jovem de 18 anos como componente principal, ele mora com seu avô e sua avó paterna, de 65 e 60 anos respectivamente, além de dois tios. As morbidades relacionadas são enxaqueca, inerente ao adolescente e sua avó, além de Hipertensão Arterial em seus avós. Ao nascer, o indivíduo foco foi abandonado por sua mãe, que separou de seu pai, deixando o menor sobre seus cuidados, e por sua vez o entregou para ser criado pelos avós.

\section{Caracterização e Análise do Discurso dos Entrevistados}

Nesta seção buscou-se desvendar e discutir as representações presentes nos achados oriundos das entrevistas semiestruturadas.

\section{Categorização e Analise do Discurso dos Adolescentes}

CATEGORIA 1 - REPRESENTAÇÕES DOS ADOLESCENTES ACERCA DA MORTE E DO MORRER

Ao se interrogar sobre a concepção que envolve a morte, os adolescentes trouxeram definições atreladas à finitude.

O discurso que permeia essa temática expressou, também, que o suicídio é uma forma achada para romper com aquilo que não está lhe fazendo bem. A morte, nesse caso, seria a possibilidade encontrada para ruptura com situações causadoras de sofrimento. 


\section{CATEGORIA 2 - O SUICÍDIO: REPRESENTAÇÕES DOS ADOLESCENTES}

No discurso dos adolescentes, o ato suicida foi resultado de uma atitude impensada, um impulso, um desatino em resposta aos sentimos de raiva e desespero.

A impulsividade acabou sendo o resultado de um momento de grande aflição, onde a pressão psicológica esteve fortemente presente, bloqueando todas as possibilidades de fuga do problema exposto.

Essa temática foi lembrada como um momento impensado, perante uma impulsividade, sendo esta permeada por inúmeros fatores, os quais devem ser identificados, precocemente, na tentativa de eliminar o risco de recidivas que, certamente, serão cada vez mais agressivas.

\section{CATEGORIA 3- EXPERIÊNCIAS DOS ADOLESCENTES COM O INTENTO SUICIDA}

A falta de habilidade para administração de sentimentos é propriedade do descontrole psicoemocional, podendo levar à depressão e intento suicida. Os adolescentes justificaram essa atitude após ter vivenciado um momento impensado, de grande raiva e desespero. Buscar a morte foi a solução encontrada para a resolução de problemas, alívio das angústias e sofrimento. O desespero foi ligado a uma desesperança de que mudanças poderão ocorrer, e viver sem essa possibilidade torna-se impossível.

Atrelado ao sofrimento, vários outros sentimentos foram associados para a constituição do desejo suicida. E, na maioria das vezes, a própria consciência alimentou ou criou fatos inimagináveis que acabaram sustentando e conduzindo ao ato.

O sentimento de culpa foi um fator relevante, o qual contribuiu para aumentar a inquietação mental, sendo, este, um episódio atenuante na tentativa de auto-extermínio.

Além de impulsiva, a tentativa de auto-extermínio foi uma retaliação a um acontecimento vivenciado, ou seja, na hora da raiva, agindo brutalmente, como uma maneira de demonstrar sua decepção.

A tentativa de auto-extermínio trouxe duas representações a serem expostas, a primeira, numa visão profunda, traduz a necessidade psicológica do individuo expressar um grito de socorro na busca de resolução de problemas, e, concretamente trata-se de um ataque à si, ao outro e ao mundo no qual está inserido.

Outro fator preponderante para o desejo do intento é a desestruturação familiar.

É, nessa complexidade que envolve o adolescer, que a presença familiar contribui no fortalecimento de vínculos, proporcionando apoio e segurança às indagações e aflições surgidas nessa 
época. E ao haver uma ruptura nessa figura familiar tudo se perde, deixando pairado um sentimento de abandono e sofrimento.

As discussões e intrigas foram os principais determinantes para o ápice desse desejo suicida, essas dificuldades em enfrentar seus conflitos os fizeram procurar tais estratégias que, para eles significou ser a forma mais rápida e simples para a resolução das suas angústias.

\section{CATEGORIA 4 - SUICIDA EM RELAÇÃO AO SEU CORPO SOCIAL: VISÃO DOS ADOLESCENTES}

Percebeu-se que a sociedade associa tal atitude como loucura, sendo as pessoas referenciadas de desocupadas e sem crenças.

A conduta social frente ao intento foi caracterizada pelo preconceito, sendo expressa pelos jovens a indignação ao destacar já terem sido rejeitados pela sociedade após a tentativa de suicídio.

A incompreensão pela sociedade da amplitude de enigmas que permeiam o ato traz aos adolescentes sensações que exprimem vergonha e anseio pela indiferença do outro. Esse estigma social acaba por vezes sendo o responsável pelo comportamento anti-social e, assim afastamento de meios importantes na ressocialização desses jovens.

\section{Categorização e Análise do Discurso das Famílias}

\section{CATEGORIA 1 -EXPERIÊNCIA DA FAMÍLIA COM O SUICÍDIO}

Vivências são situações marcadas por percepções que proporcionam acúmulo de conhecimentos, levando ao amadurecimento e expressão de emoções. E, ao presenciar seu familiar passar por um ato de tão grande desespero, que o levou a tomar a decisão de tentar contra sua própria vida, os sentimentos experimentados acabam sendo fortemente negativos.

Ao deparar-se com o intento suicida, a ação da família foi caracterizada pela aflição do momento, devido ao risco de morte iminente, bem como pela posterior revolta e incompreensão do ato, associado também à preocupação com os fatores que levaram ao intento.

Dessa forma, o suicídio acaba sendo reflexo da intraquilidade entre o corpo e a alma, caracterizando essa situação como um grito de ajuda. E, a primeira atitude frente à essa súplica, é a busca pela ajuda profissional.

Ao se compreender a multicausalidade que envolve todos esses aspectos, a estratégia encontrada pela família para ajudar na superação do trauma foi o diálogo. Sendo um mecanismo 
básico para a aproximação entre seus membros, além de peça fundamental para a prevenção de outras situações similares à esta.

\section{CATEGORIA 2 - PERCEPÇÃO DA FAMÍLIA ACERCA DO CUIDADO AO SUICIDA NA EMERGÊNCIA HOSPITALAR}

O cuidado é um ato característico dos seres vivos, e, sua existência é atrelada aos primórdios, sendo associado à figura materna. Expressa-se como arte inerente à enfermagem que, amparada numa visão holística se propõe a, não só buscar a cura, mas opta por assistir ao paciente em todas as suas necessidades.

O desejo das famílias diante do intento suicida se resume ao encontro de apoio e atenção direcionado ao jovem. Ao mesmo tempo, os familiares precisam de um feedback da assistência prestada, na ânsia pelo bem estar de seu ente.

No que concerne à essa visão, a assistência ao jovem e sua família foi marcada pela agilidade que os procedimentos técnicos foram realizados. Sendo esta uma marca da própria dinâmica da emergência, local de situações imprevisíveis, tendo como prioridade o uso de tecnologias duras para estabilização e diminuição de danos ao paciente.

Contudo, a continuidade da assistência não foi estabelecida, a ânsia por satisfação e acompanhamento de seus entes ficou muito a desejar, o que manifestou sentimentos de insegurança quanto a assistência. A aversão foi estendida ao lembrar a postura de alguns profissionais perante o intento suicida, o que comprovou a ausência de ética profissional ao menosprezar o acontecido.

Essa falta de humanização associada à priorização da tecnicidade de procedimentos observada nas expressões, foi o que contribuiu para a percepção negativa dos familiares.

Diante da angústia exposta pelo conjunto das experiências vividas, foi relevante a presença da fé na interseção divina, estando associado ao atendimento prestado. Mas, mesmo com o apoio vindo do alto, o atendimento não obteve total grau de satisfação, principalmente quando se lembra a importância da integralidade da assistência para a continuidade do tratamento.

\section{Considerações Finais}

Esta pesquisa possibilitou a compreensão dos determinantes socioculturais e da dinâmica afetivo relacional na produção do desejo suicida em adolescentes, fornecendo subsídios para ações preventivas a serem efetivadas de forma integrada, envolvendo outros protagonistas contexto assistenciais da rede de apoio, dentre eles, as famílias, o ambiente hospitalar, o poder público e as 
pessoas da comunidade a fim de que possam identificar e minimizar o potencial de risco de recidiva para o suicídio e promover a reabilitação psicossocial.

\section{Referências}

BRASIL. Conselho Nacional de Saúde. Resolução no 196, de 10 de outubro de 1996. Conselho Nacional de Ética em Pesquisa. Diretrizes e Normas Reguladoras de Pesquisa Envolvendo Seres Humanos. Bioética. Brasília [DF], 1996.

Ministério da Saúde, Secretaria de Atenção à Saúde. Área de saúde do Adolescente e do Jovem. Marco legal: saúde, um direito de adolescente. Brasília: M. S., 2007.

FIORIN, J. L. Elementos de análise do discurso. 13. ed. São Paulo: Editora Contexto. 2005.

FROTA, A. M. M. C. Diferentes Concepções da infância e adolescência: a importância da historicidade para a sua construção. Estud. pesqui. psicol. (Impr.), v. 7, n. 1, p. 147-160, jan./jun. 2007. Disponível em: 〈http://www.revispsi:uerj.br>. Acesso em: 14 mar. 2013.

KRONKA, G. Z. Análise do discurso e lingüística textual: interação e interdiscursividade. Encontro do Celsul5. Curitiba-PR, Anais. 2003 (589-594). Disponível em: <http://www.celsul.org.br/Encontros/05/pdf/081.pdf>. Acesso em: 4 set. 2012.

NUNES, E. 1. G; ANDRADE, S. G. adolescentes em situação de rua: prostituição, drogas e HIV/AIDS em Santo André, BRASIL. Psicologia \& Sociedade; v. 21, n. 1, p. 45-54, 2009. Disponível em: <http://www.scielo.br/pdf/psoc/v21n1/06.pdf >. Acesso em: 5 nov. 2012.

SOUZA, L. D. M.; ORES, L.; OLIVEIRA, G. T.; CRUZEIRO, A. L. S.; SILVA, R. A.; RICARDO TAVARES PINHEIRO, R. T.; HORTA, B. L. Ideação suicida na adolescência: prevalência e fatores associados. J. bras. psiquiatr., Rio de Janeiro, v. 59, n. 4, 2010 . Disponível em: <http://www.scielo.br/scielo.php〉. Acesso em: 14 maio 2012.

WALKER, D. Juazeiro do Norte: a terra do Padre Cícero. Juazeiro do Norte: Gráfica Padre Cícero, 2002.

\section{Como citar esse artigo (ABNT):}

GONÇALVES, N.D.; RANDEMARK, N.F.R. Suicídio na Adolescência: Representações dos pacientes e suas famílias. Id on Line Revista de Psicologia, Julho de 2014, vol.8, n.23, p254-267. ISSN 1981-1179. 